\title{
A Multiple Timepoint Pre-post Evaluation of a 'Sexual Respect' DVD to Improve Competence in Discussing Sex with Patients with Disability
}

\author{
Kerry Dyer • Aimee Aubeeluck • Nicola L. Yates • Roshan Das Nair \\ K. Dyer (\&) \\ Department of Clinical Psychology and Neuropsychology, Queens Medical Centre, Nottingham \\ University Hospitals NHS Trust, Nottingham NG7 2UH, England \\ e-mail: kerry dyer@hotmail.co.uk
}

A. Aubeeluck

Faculty of Medicine and Health Sciences, Royal Derby Hospital, Derby DE22 3DT, England

N. L. Yates

Derbyshire Healthcare NHS Foundation Trust, Derby, England

\author{
R. Das Nair \\ Division of Psychiatry and Applied Psychology, Division of Rehabilitation and Ageing, University \\ of Nottingham, Nottingham, England
}

Keywords Disability . Sexuality . Nursing education . Training . United Kingdom

Abstract Sexual problems are common after chronic illnesses and disability, yet research indicates that this is a neglected area in healthcare services. Evaluation studies provide evidence of the effectiveness of education in enhancing professionals' knowledge, skills, and comfort in addressing patients' sexual concerns. However, there are limited evaluations aimed at improving ability to discuss sexuality when working with people with disabilities. The overall aim of this study was to evaluate a 'Sexual Respect' DVD as an intervention to improve competence in addressing 'sexuality and disability'. A mixed methods design was used with both quantitative and qualitative components. Nursing students' self-report ratings of knowledge, confidence, comfort and willingness (to discuss sexuality) levels were collected across four time points: baseline, pre-intervention, post-intervention, and follow-up. Data were analysed using one-way repeated measures ANOVAs with post hoc comparisons. Open-ended qualitative comments relating to the barriers and facilitators to discussing sexuality were analysed using content analysis and subsequent frequency analysis. Reported barriers included lack of knowledge about sexuality and disability issues, the patient's level of disability, and waiting for the patient to raise sexuality issues first. Facilitators included education/training, written information, and if the patient raised it first. Overall, the DVD intervention had a significant and positive impact on nursing students' self-reported knowledge, confidence, comfort and willingness levels. The findings are discussed in relation to the PLISSIT model, which emphasises the importance of a proactive approach to addressing sexuality issues.

\section{Background}

Sexuality 
Sexuality has been defined as the way that people experience themselves and each other as sexual beings [1]. This encompasses sexual activity, sexual orientation, gender identity and roles, eroticism, pleasure, intimacy, and reproduction [2]. Sexual wellbeing is increasingly considered an integral component of the total wellbeing of a person; for example, it is

highlighted as a component of healthcare in the International Classification of Functioning, Disability and Health (ICF [3], and in the Department of Health (DoH)'s White Paper: Healthy Lives, Healthy People [4]. Sexuality is now identified as a fundamental and natural need within everyone's life regardless of age or physical state [5]. Disturbances to sexuality and sexual function can cause frustration, anxiety, depression, and affect overall quality of life [6].

\section{Disability}

The International Classification of Functioning, Disability and Health (ICF), adopted as the conceptual framework for this article, defines disability as an umbrella term covering impairments (problems in body function or structure), activity limitations, and participation restrictions [3]. Disability refers to the negative aspects of the interaction between individuals with a health condition, and personal and environmental factors (e.g. negative attitudes, inaccessibility of transport and public buildings, and limited social support) [4].

More than a billion people are estimated to live with some form of disability, which equates to $15 \%$ of the world's population (based on 2010 figures). Of these, 110 million people $(2.2-3.8 \%)$ are estimated to have very significant difficulties in functioning or 'severe disability' (e.g. quadriplegia, severe depression, or blindness). The number of people with disabilities is increasing due to the ageing population, and due to the increase in chronic health conditions (e.g. diabetes, cardiovascular diseases, mental illness) [4].

\section{Sexuality and Disability}

Sexual problems are common after chronic illnesses and disability, as acknowledged in the Royal College of Nursing (RCN)'s Sexual Health Strategy [7]. An estimated $72 \%$ of people with disability experience sexual problems, with only $18 \%$ able to overcome these independently [8]. Sexual problems have been found to be common in people who have experienced variety of health related diagnoses, such as stroke [9], multiple sclerosis [10], and head injury [11].

Studies exploring the experiences of people with physical disability suggest that body changes and impaired bodily functions complicate the person's social and sexual life, which can affect self-esteem, body image, relationships, and sexual functioning [12]. Many people report challenges in meeting a partner, along with worries about isolation and being unable to experience affection, touch, or intimacy [13-20]. Studies indicate that patients with physical disabilities are dissatisfied with the amount and quality of information and support around sexual function [21]. This is inadequate given that sexual satisfaction has been found to be a strong predictor of overall psychological wellbeing [14].

\section{Management in Healthcare}

Despite acknowledgement of disturbance to sexuality in people with disabilities, the existing research indicates that it is a neglected area in healthcare. For example, one study found that although $90 \%$ of healthcare professionals agreed that sexual issues ought to be 
addressed as part of the holistic care of patients, $94 \%$ were unlikely to discuss sexual issues [22]. This highlights that there is a conflict between staff ideology and practice.

This is of concern as the National Sexual Health Strategy [4] included the drive for more attention to be paid to the assessment of sexual and relationship needs, and was explicit about the services and treatments that people could expect to receive. Furthermore, the RCN [7] highlights that "nurses need to recognise that sexuality and sexual health are legitimate areas of nursing activity and that nurses have a professional and clinical responsibility to address them"(p. 5).

\section{Professionals' Perspective}

Research indicates that professionals are reluctant to address sexuality because of: Perceived lack of knowledge and skills; lack of resources, time and policy; fear of causing offence; personal embarrassment and discomfort; believing it is not their responsibility and perceiving that patients are too ill or unwilling to discuss sexual issues [22-29].

In addition, professionals do not consider sexuality a priority in the context of patients' other problems such as 'walking and talking' [29-32]. Whilst these perceptions are likely to be congruent with patients' expectations in acute settings, they cannot be avoided in rehabilitation and community settings. In such settings, healthcare input often lasts months or years and patients are in a stage of recovery whereby they are attempting to get back to their normal life. Therefore, it is perhaps not surprising that research shows that patients $d o$ want and expect professionals to discuss sexuality issues [33, 34].

Related to this, professionals have highlighted that sexuality is not included on routine measures of functional and rehabilitation outcome (i.e. paper-based indicators of 'success' And 'quality of care') compared to other rehabilitation issues like "walking and talking" [29] The professionals believed that this sexuality as low priority within their organisation, and therefore they feel less obliged to address it. This represents an NHS culture that places high value on financially driven targets, set centrally by the Department of Health. Overcoming this culture was an important lesson learnt from the Francis report [35].

\section{Sexuality and Disability Education}

Clinicians and researchers have highlighted the need for education in the area of sexuality and disability [22, 28, 36-41]. Furthermore, it has been argued that education should be provided early in the clinicians' career, before negative attitudes and stereotypes have been developed [42-44]. Evaluation studies provide evidence of the effectiveness of education in enhancing knowledge, skills, and comfort in addressing patients' sexual concerns [21, 4551]. However, there are limited evaluations aimed at improving clinicians' ability to discuss sexuality when working with people with disabilities [25]. Therefore, when the Sexual Respect DVD was produced by the Sexual Health and Disability Alliance (SHADA) ${ }^{1}$ to encourage clinicians to address sexuality with their disabled patients, we were approached to evaluate the effectiveness of this DVD.

\section{Aims}

The aim of the study was to:

1. Investigate the impact of the DVD on nursing students' self-reported knowledge, confidence, comfort, and willingness to address sexuality issues with patients with disabilities. 
2. Explore nursing students' perceived barriers and facilitators to discussing sexuality issues with patients with disabilities.

\section{Methods}

\section{Design}

A primary multiple timepoint pre-post quantitative design with a nested qualitative component was used.

\section{Sample}

A convenience sample of nursing students from the East Midlands were recruited for the study. An initial email was sent to two cohorts of nursing students (one cohort of first year students and one cohort of second year students) inviting them to take part in the evaluation. They were informed that time would be given during their usual teaching to complete the questionnaires and view the DVD, and therefore participation was optional and would not require an additional time commitment. One hundred and thirty-eight participants took part in the study. The participants were between 21 and 46 years of age and the majority were female $(85.5 \%)$. Further demographic characteristics are presented in Table 1.

\section{The DVD}

The 30-minute DVD contains information on the types of sexual problems that people with disabilities face (including those of a physical, psychological, and social nature), tips for opening up conversation about sexual issues with patients with disabilities, and information on self-help and peer-support groups that patients can be signposted on to. This information is presented by clinicians and people with disabilities themselves. ${ }^{2}$

1 SHADA was formed in 2005 by the Outsiders Trust, a registered British charity, to bring together professionals who work with disabled people.

2 For more details and to view the DVD, please visit http://www.sexualrespect.com. 
Table 1 Demographic data of participants $(\mathrm{n}=138)$

\begin{tabular}{ll} 
Participants & Frequency \\
\hline Gender & \\
Female & $118(85.5 \%)$ \\
Male & $20(14.5 \%)$ \\
Age & \\
Mean ( \pm SD) & $26.9( \pm 5.5)$ \\
Range & $21-46$ \\
$21-30$ years & $98(80.3 \%)$ \\
$31-40$ years & $19(15.6 \%)$ \\
$41-50$ years & $5(4.1 \%)$ \\
Race & \\
White British & $114(82.6 \%)$ \\
White Irish & $2(1.4 \%)$ \\
White (other) & $1(0.7 \%)$ \\
Mixed & $7(5 \%)$ \\
Indian & $4(2.9 \%)$ \\
Black-Caribbean & $3(2.2 \%)$ \\
Black-African & $6(4.3 \%)$ \\
Would rather not say & $1(0.7 \%)$ \\
Sexuality & \\
Heterosexual & $127(92 \%)$ \\
Lesbian & $2(1.4 \%)$ \\
Gay & $1.4(2 \%)$ \\
Other & $1(0.7 \%)$ \\
Would rather not say & $1(0.7 \%)$ \\
Religion & \\
None & \\
Christian & $70(50.7 \%)$ \\
Sikh & $51(37 \%)$ \\
Buddhist & $3(2.2 \%)$ \\
Other & $6(4.3 \%)$ \\
Would rather not say & $4(2.9 \%)$ \\
Disability & $1(0.7 \%)$ \\
No known disability & \\
Specific learning disability & $114(82.6 \%)$ \\
Longstanding illness & $10(7.2 \%)$ \\
Mental health condition & $6(4.3 \%)$ \\
Other & $1(0.7 \%)$ \\
Would rather not say & $4(2.9 \%)$ \\
&
\end{tabular}

Data were collected using a purpose-designed questionnaire. The questionnaire was divided into three sections: 
1. Demographic information.

2. Questions designed to measure the levels of self-rated knowledge, confidence, comfort and willingness to discuss sexuality with patients with disabilities. These variables were chosen because perceived knowledge, confidence, and comfort have been shown to be key predictors of willingness to discuss sexuality [40, 51, 52]. Responses were provided on a 10-point Likert scale (10 being the most knowledgeable/confident etc).

3. Open-ended questions, with free-text options, to gain information on the perceived barriers and facilitators to discussing sexuality (time 1 only).

Participants completed the baseline questionnaire (time 1). Two weeks later (immediately prior to viewing the DVD), participants completed the pre-intervention questionnaire (time 2). The DVD was then shown to participants, followed by completion of the post-intervention questionnaire (time 3). Two weeks later, participants completed the follow-up questionnaire (time 4). A self-generated participant ID code was used to track participant responses across the four timepoints. Data were collected over eight months during 2012-2013.

\section{Ethical Considerations}

Ethical approval for the study was granted by the University of Lincoln. Participants were informed verbally and in writing about the purpose of the evaluation, that their participation was entirely voluntary, and that the results would remain anonymous through the use of a self-generated participant ID code. They were also informed that they would receive a debrief email summarising the results of the evaluation. Participants were reminded of their right to withdraw their data if they wished to do so. Return of the questionnaires was taken as implied consent.

\section{Data Analysis}

One-way repeated measures ANOVAs and post hoc comparisons (using SPSS version 20.0) were used to determine whether there was a change in knowledge, confidence, comfort, and willingness scores over the four time-points.

Responses to the open-ended questions were analysed using traditional content analysis, which involved 'chunking' participants' responses into categories through a process of iterative (open) coding [53]. In the event that a participant's response fitted more than once category, it was split and included in both. Pre-conceived categories were not used in order to ensure that analysis remained firmly grounded in the data. This was followed by a descriptive statistical analysis (frequency analysis) of the categorised answers, as described by Bauer [54]. This approach could be deemed reductionist, but it was deemed appropriate given that the aim of the evaluation was to provide a summary of the trends in the manifest (easily identifiable) content of the data.

\section{Validity and Reliability}

The internal consistency of the two 'Knowledge' items and three 'Confidence' items were assessed by Cronbach's alpha. This yielded scores of 0.874 (Knowledge) and 0.873 (Confidence), indicating that the items were highly consistent with each other and by implication, were assessing the same construct. This also meant it was appropriate to calculate the mean of the items which made up these constructs. There was only one 'Comfort' item and one 'Willingness' item, hence they were not grouped. 


\section{Findings}

Analysis

\section{Pre-post Intervention Comparison}

Data were initially screened for outliers and missing data. Cases were excluded list wise where data were missing, thus the number of participants included was 65 for the knowledge and confidence variables and 64 for the comfort and willingness variables.

The analysis indicated that there were significant differences over time on knowledge, confidence, comfort and willingness (Table 2; Fig. 1). The difference was between time 2 and time 3 on all four variables. Furthermore, there was no difference between time 1 and time 2 on all four variables which increases confidence in attributing the increases to the DVD intervention. Finally, there were no significant differences between times 3 and 4 on knowledge, confidence and willingness, indicating that they were maintained at follow-up. Scores on comfort increased between times 3 and $4(p<0.05)$, which could be due to a number of reasons including delayed benefits of the DVD, or other intervening variables (e.g., placement or teaching opportunities that related to sexuality and/or disability issues).

\section{Questionnaire Comments}

Perceptions of the DVD were identified via content analysis and subsequent frequency analysis of the open-ended questions. This enabled us to determine which themes appeared and how frequently. The five most frequent categories for each question are provided below.

Barriers to Discussing Sexuality with Patients Out of the 81 comments from the participants, lack of knowledge of sexuality and disability issues was cited as a barrier 39 times (48\%). The participants also identified that the patient's level of disability would affect whether they raise sexual issues with them $(10 \%)$. Other barriers related to waiting for the patient to raise sexuality issues first $(7 \%)$, a fear of offending the patient $(6 \%)$, and not knowing where to refer patients on to (i.e. signposting issues) $(5 \%)$.

Facilitators to Discussing Sexuality with Patients Out of 62 comments, education/ training was cited as a facilitating factor to discussing sexuality 39 times (64\%). The participants also identified that access to written information leaflets would help them to raise sexuality issues with patients (10\%), as well as if the patient raised sexuality issues

Table 2 One-way repeated measures ANOVA with pairwise comparisons

\begin{tabular}{|c|c|c|c|c|c|c|c|}
\hline \multirow[t]{2}{*}{$\overline{\text { Variable }}$} & \multicolumn{4}{|c|}{ Repeated measures ANOVA } & \multicolumn{3}{|c|}{ Pairwise comparisons } \\
\hline & $\mathrm{n}$ & $\mathrm{F}$ & $p$ & & $\begin{array}{l}p(\text { time } 1 x \\
\text { time } 2)\end{array}$ & $\begin{array}{l}p(\text { time } 2 \times \\
\text { time } 3)\end{array}$ & $\begin{array}{l}p \text { (time } 3 x \\
\text { time } 4)\end{array}$ \\
\hline Knowledge & 65 & $(3,62) 69.558$ & 0.000 & $(+++)$ & $0.825(\mathrm{NS})$ & 0.000 & $1.000(\mathrm{NS})$ \\
\hline Confidence & 65 & $(3,62) 36.645$ & 0.000 & $(+++)$ & $1.000(\mathrm{NS})$ & $0.000 \quad(+++)$ & $0.209(\mathrm{NS})$ \\
\hline Comfort & 64 & $(3,61) 32.029$ & 0.000 & $(+++)$ & $0.303(\mathrm{NS})$ & $0.000 \quad(+++)$ & $0.037(++)$ \\
\hline Willingness & 64 & $(3,61) 30.515$ & 0.000 & $(+++)$ & $1.000(\mathrm{NS})$ & 0.000 & $0.069(\mathrm{NS})$ \\
\hline
\end{tabular}

NS not significant

$++p<0.01 ;+++p<0.001$ 
Fig. 1 Graph showing nursing students' knowledge, confidence, comfort, and willingness to address sexuality issues over the four time-points

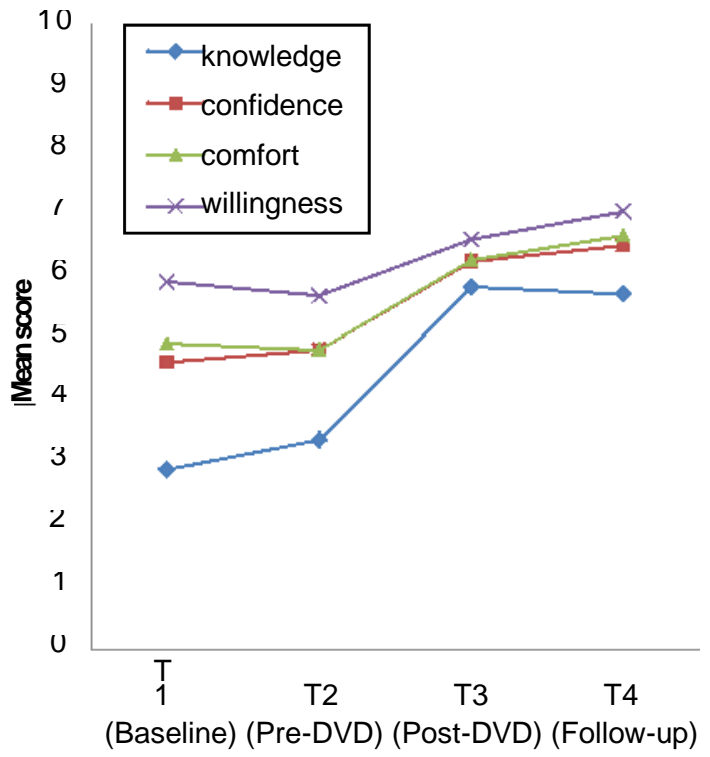

first (7\%), if there was a structured procedure for asking about sexuality issues (5\%), and if they had built a trusted relationship/rapport with the patient first.

\section{Discussion}

Sexuality is an area which many healthcare professionals may be reluctant to address, particularly with patients with a disability. This study evaluated the effectiveness of a Sexual Respect DVD, with the aim of assessing whether it would be a useful training tool for nursing students to improve their knowledge, confidence, comfort, and willingness to address sexuality with people with disabilities.

\section{Barriers and Facilitators to Discussing Sexuality}

Some participants commented that they would be less inclined to raise sexual issues with patients with more severe physical and/or learning disabilities. It was not clear what beliefs underpinned these comments, but is could represent the categorisation of these patients as "asexual". Indeed this viewpoint has been highlighted in the literature [28, 55]. This is concerning given that sexuality is identified as a fundamental and natural need within everyone's life [6], along with the known importance of sexuality for overall quality of life $[56,57,58]$, and the professional and clinical responsibility of nurses to address sexual issues [7].

Some participants highlighted that they would not raise sexual issues for fear of offending the patient. This perceived topic sensitivity has been identified by previous research [28, 29, 37, 59, 60]. However, research indicates that most patients are not offended by discussions of sexuality [40, 61], and do expect professionals to make inquiries about sexuality issues [21]. 
Some participants highlighted that they would wait for the patient to raise sexual issues first, a finding consistent with previous research [29, 62, 63]. However, this reactive approach is considered problematic given evidence that patients believe that it is the professionals' role to start the conversation [64]. A more proactive approach to raising sexuality issues is therefore recommended.

A large proportion of participants believed that training/education would enable them to overcome these barriers and address sexual issues more proactively, which is consistent with findings from previous research [22, 28, 29, 37, 65]. The Sexual Respect $D V D$ offers one way of addressing this need. Participants also commented that a standardised procedure for enquiring about sexual issues would also help them to raise sexual issues with patients, which again is consistent with previous research $[28,29,65$, 66]. Tools such as these may help to create a more facilitative healthcare environment which grants "per-mission"to both nurses and patients to raise and discuss sexual issues in relation to their disability.

\section{Pre-post Intervention Comparison}

The analysis indicated that overall, the DVD improved nursing students' knowledge, confidence, comfort, and willingness to address sexuality issues with people with disability. This is consistent with previous research highlighting the benefit of sexuality education for professionals more generally [21, 45-51].

We use the theory of self-efficacy to understand this change in reported behaviours. This theory asserts that all forms of behavioural change operate through a common mechanism: The alteration of the individual's expectations of personal mastery and success over the behaviour in question [67]. Professionals are unlikely to perform a task if they believe they will be unsuccessful. In contrast, if professionals believe that they can successfully perform a task (i.e. confidence to discuss sexuality issues), then this will then affect their motivation to do so (willingness).

\section{A Model for Clinical Practice}

The PLISSIT model [68] has been used over the past 30 years by professionals working to address the sexual wellbeing of individuals with acquired disability and chronic illnesses [69], and has also been used as a framework for sexuality education [12]. The acronym PLISSIT signifies the four levels of intervention: Permission to discuss sexuality, provision of Limited Information regarding sexuality, Specific Suggestions regarding the person's sexual issues, and Intensive Therapy with an expert when needed. The DVD was aimed at getting participants to level one, permission-giving, where they would be attentive and comfortable enough to let patients know that sexuality is a legitimate area for discussion, thus enabling patients to be open about their sexual concerns. Indeed, permission-giving has been found to be such a significant aspect of sexuality education that the revised and extended model (the Ex-PLISSIT model) emphasises that all levels should begin with this explicit permission-giving $[69,70]$.

Whilst the DVD appears to have had a positive impact, further intervention is perhaps needed so that nursing students feel able to intervene at the higher levels. It is also important to note that getting sexuality issues onto the healthcare agenda is dependent on much more than nurses' motivation. On-going organisational support is needed in the form of training, time and appropriate resources to enable nurses to address sexuality issues in their day-to-day practice. Policy should also be developed to enable nurses to identify 
levels of competence and the professional boundaries of their work [71]. Employers should also create opportunities for professionals to have open discussion of their values, attitudes and comfort levels in relation to sexuality [29]. This could take the form of reflective practice groups. Mentoring and clinical supervision within the practice environment, with opportunities to observe others and receive feedback on one's own practice, may provide additional ways to enhance confidence, comfort and willingness levels [12]. However, it could also be argued that wider societal views, including the categorisation of people with disabilities as 'asexual' and 'undesirable', needs addressing on a larger scale [72].

\section{Study Limitations}

The project's use of a mixed-methodology design has provided rich insight into the potential usefulness of a DVD intervention for helping clinicians to address sexuality issues. However, there are a number of limitations. It is not possible to state with certainty that changes between times 2 and 3 are indeed effects of the DVD, particularly as there was no control group with which to compare. However, it seems unlikely that spontaneous changes would occur. The use of multiple baselines (which shows relative stability) increases our confidence in this conclusion.

Secondly, the sample size was relatively small and was limited in that it was a convenience sample and not randomly selected. The sample was also non-representative of all clinicians working with people with disability in healthcare. Future evaluations could examine the effectiveness of the DVD for qualified nurses, as well as with professionals from other disciplines who work with people with disabilities (e.g. medical, occupational therapy, and physiotherapy). This would also allow for comparisons across other disciplines.

The reliance on self-reporting may have created a bias, with participants wishing to present more favourably on their increase of knowledge, confidence, comfort and willingness. Social desirability may also have meant that participants selected responses that they felt were desired response, instead of selecting the response most appropriate to themselves. However, we attempted to minimise this by keeping the responses anonymous.

Finally, the evaluation only captured participant-reported outcomes of the DVD. Future studies would benefit from the inclusion of behavioural measures of professionals' interactions with patients on sexuality and disability issues. This would allow evaluation of the application and transferability of the knowledge and skills gained. Future research could also look at whether the DVD has an impact in modifying attitudes towards sexuality of people with disabilities; authors have reported positive changes in attitudes, following sexuality workshops delivered to an interdisciplinary team $[51,65]$.

\section{Conclusion}

This study aimed to evaluate a 'Sexual Respect' DVD as an intervention to improve competence in addressing sexuality issues in people with disabilities. Pre-post intervention assessments, over four time points, indicated that the intervention had a significant and positive impact on nursing students' self-reported knowledge, confidence, comfort and willingness (to discuss sexuality) levels. 
Acknowledgments This research received no specific Grant from any funding agency in the public, commercial, or not-for-profit sectors. The 'Sexual Respect' DVD was provided by the Sexual Health and Disability Alliance (SHADA).

Conflict of interest No conflict of interest has been declared by the authors.

\section{References}

1. Rathus, S.A., Nevid, J.S., Fichner-Rathus, L., Herold, E.S., McKenzie, S.W.: Human Sexuality in a World of Diversity, 2nd edn. Pearson Education, New Jersey (2005)

2. World Health Organization.: Sexuality: draft working definition. http://www.who.int/reproductivehealth/ topics/gender_rights/sexual_health/en/ (2014). Accessed 4 January 2014

3. World Health Organisation: International Classification of Functioning, Disability and Health. World Health Organisation, Geneva (2001)

4. World Health Organisation: World Report on Disability. World Health Organisation, Geneva (2011)

5. Department of Health: The National Strategy for Sexual Health and HIV. Department of Health, London (2001)

6. Pangman, V.C., Sequire, M.: Sexuality and the chronically ill older adult: a social justice issue. Sex. Disabil. 18, 49-59 (2000)

7. Royal College of Nursing: RCN Sexual Health Strategy: Guidance for Nursing Staff. RCN, London (2001)

8. Stewart, W.F.R.: Sex and the Physically Handicapped Person. National Fund for Research into Crippling Diseases, London (1975)

9. Kimura, M., Murata, Y., Shimoda, K., Robinson, R.: Sexual dysfunction following stroke. Compr. Psychiatry 42(3), 217-222 (2001)

10. Minderhoud, J.M., Leemhuis, J.G., Kremer, J., Laban, E., Smits, P.M.: Sexual disturbances arising from multiple sclerosis. Acta Neurol. Scand. 70(4), 299-306 (1984)

11. Elliott, M.L., Biever, L.S.: Head injury and sexual dysfunction. Brain Inj. 10(10), 703-717 (1996)

12. Higgins, A., Barker, P., Begley, C.: 'Veiling sexualities': a grounded theory of mental health nurses responses to issues of sexuality. J. Adv. Nurs. 62(3), 307-317 (2008)

13. Tepper, M.: Sexuality and disability: the missing discourse of pleasure. Sex. Disabil. 18(4), 283-290 (2000)

14. Taleporos, G., McCabe, M.P.: The impact of sexual esteem, body image, and sexual satisfaction on psychological well-being in people with physical disability. Sex. Disabil. 20(3), 177-183 (2002)

15. Koch, T., Kralik, D., Eastwood, S.: Constructions of sexuality for women living with multiple sclerosis. J. Adv. Nurs. 39(2), 137-145 (2002)

16. Gagliardi, B.A.: The experience of sexuality for individuals living with multiple sclerosis. J. Clin. Nurs. 12(4), 571-578 (2003)

17. McCabe, M., McDonald, E.: Perceptions of relationship and sexual satisfaction among people with multiple sclerosis and their partners. Sex. Disabil. 25(4), 179-188 (2005)

18. Singh, R., Sharma, S.: Sexuality and women with spinal cord injury. Sex. Disabil. 23(1), 21-33 (2005)

19. Ward, N.: Assessment and management of sexual dysfunction in women with multiple sclerosis. Br. J. Neurosci. Nurs. 1(2), 75-80 (2005)

20. Esmail, S., Munro, B., Gibson, N.: Couple's experience with multiple sclerosis in the context of their sexual relationship. Sex. Disabil. 25(4), 163-177 (2007)

21. Gianotten, W., Bender, J., Post, M., Hoing, M.: Training in sexology for medical and paramedical professionals: a model for the rehabilitation setting. Sex. Relatsh. Ther. 21(3), 303-317 (2006)

22. Haboubi, N.H.J., Lincoln, N.: Views of health professionals on discussing sexual issues with patients. Disabil. Rehabil. 25(6), 291-296 (2003)

23. Herson, L., Hart, K., Gordon, M.J., Rintala, D.H.: Identifying and overcoming barriers to providing sexuality information in the clinical setting. Rehabil. Nurs. 24(4), 148-151 (1999)

24. Booth, S., Kendall, M., Fronek, P., Miller, D., Geraghty T, T.: Training the interdisciplinary team in sexuality rehabilitation following spinal cord injury: a needs assessment. Sex. Disabil. 21(4), 249-261 (2003)

25. Higgins, A., Sharek, D., Nolan, M., Sheerin, B., Flanagan, P., Slaicuinaite, S., Mc Donnell, S., Walsh, H.: Mixed methods evaluation of an interdisciplinary sexuality education programme for staff working with people who have an acquired physical disability. J. Adv. Nurs. 68(11), 2559-2569 (2012) 
26. Baker, M., Shears, S.: Sexuality training for health and social care professionals working with people with an acquired brain injury. Soc. Care. Neurodisabil. 1(3), 4-12 (2010)

27. Akinci, A.C., Yildiz, H., Zengin, N.: The level of comfort among nursing students during sexual counseling to patients who have chronic medical conditions. Sex. Disabil. 29(1), 11-20 (2011)

28. Dyer, K., das Nair, R.: Why don't healthcare professionals talk about sex? A systematic review of recent qualitative studies conducted in the United Kingdom. J. Sex. Med. 10, 2658-2670 (2013)

29. Dyer, K., das Nair, R.: Talking about sex after traumatic brain injury: perceptions and experiences of multidisciplinary rehabilitation professionals. Disabili. Rehabil. Epub ahead of print. http:// informahealthcare.com/doi/abs/10.3109/09638288.2013.859747 (2013b). Accessed 4 January 2014

30. Hordern, A.J., Street, A.F.: Communicating about patient sexuality and intimacy after cancer: mismatched expectations and unmet needs. Med. J. Aust. 186(5), 224-227 (2007)

31. Price, B.: Sexuality: raising the issue with patients. Cancer Nurs. Pract. 9(5), 29-35 (2010)

32. Zeng, Y.C., Liu, X., Loke, A.Y.: Addressing sexuality issues of women with gynaecological cancer: Chinese nurses' attitudes and practice. J. Adv. Nurs. 68(2), 280-292 (2011)

33. Waterhouse, J., Metcalfe, M.: Attitudes towards nurses discussing sexual concerns with patients. J. Adv. Nurs. 16, 54-1048 (1991)

34. Northcott, R., Chard, G.: Sexual aspects of rehabilitation: the client's perspective. Br. J. Occup. Ther. 63, 412-418 (2000)

35. Francis, R.: Report of the Mid Staffordshire NHS Foundation Trust Public Inquiry. The Stationery office, London (2013)

36. Lewis, S., Bor, R.: Nurses' knowledge of and attitudes towards sexuality and the relationship of these with nursing practice. J. Adv. Nurs. 20(2), 251-259 (1994)

37. Katz, S., Aloni, R.: Sexual dysfunction of persons after traumatic brain injury: perceptions of professionals. IJRR 22(1), 45-53 (1999)

38. Stokes, T., Mears, J.: Sexual health and the practice nurse: a survey of reported practice and attitudes. Br. J. Fam. Plann. 26(2), 89-92 (2000)

39. McLaughlin, J., Cregan, A.: Sexuality in stroke care: a neglected quality of life issue in stroke rehabilitation? A pilot study. Sex. Disabil. 23(4), 213-226 (2005)

40. Rubin, R.: Communication about sexual problems in male patients with multiple sclerosis. Nurs Stand. 19(24), 33-37 (2005)

41. Juergens, M.H., Miller Smedema, S., Berven, N.L.: Willingness of graduate students in rehabilitation counseling to discuss sexuality with clients. Rehabil. Couns. Bull. 53(1), 34-43 (2009)

42. Leaviss, J.: Exploring the perceived effect of an undergraduate multiprofessional educational intervention. Med. Educ. 34(6), 483-486 (2000)

43. Barr, H.: Interprofessional Educations: Today, Yesterday and Tomorrow. Occasional Paper No. 1. Learning and Teaching Support Network Centre for Health Sciences and Practice, London (2002)

44. Ker, J., Mole, L., Bradley, P.: Early introduction to inter-professional learning: a simulated ward environment. Med. Educ. 37(3), 248-255 (2003)

45. Cohen, G.S., Byrne, C., Hay, J., Schmuck, M.L.: Assessing the impact of interdisciplinary workshop in human sexuality. J. Sex. Educ. 20(1), 56-68 (1994)

46. Weerakoon, P.: Sexuality education for allied health professionals: a program to meet individual student needs. J. Sex. Educ. Ther. 20(1), 41-46 (1994)

47. Cohen, G.S., Byrne, C., Hay, J., Schmuck, M.L.: An eighteen month follow up on the effectiveness of a sexuality workshop: some methodological pitfalls. J. Sex Marital Ther. 22(1), 3-8 (1996)

48. Walker, B.L., Harrington, D.: Effects of staff training on staff knowledge and attitudes about sexuality. Educ. Gerontol. 28(8), 639-654 (2002)

49. Simpson, G., Anwar, S., Wilson, J., Bertapelle, T.: Improving the rehabilitative management of client sexual health concerns after neurological disability: evaluation of a staff sexuality training programme in New Zealand. Clin. Rehabil. 20(10), 847-859 (2006)

50. Post, M.W., Gianotten, W.L., Heijnen, L., Lambers, E.J., Willems, M.: Sexological competence of different rehabilitation disciplines and effects of a discipline-specific sexological training. Sex. Disabil. 26(1), 3-14 (2008)

51. Fronek, P., Booth, S., Kendall, M., Miller, D., Geraghty, T.: The effectiveness of a sexuality training program for the interdisciplinary spinal cord injury rehabilitation team. Sex. Disabil. 23(2), 51-63 (2005)

52. Katz, A.: Do ask, do tell: why do so many nurses avoid the topic of sexuality. Am. J. Nurs. 105(7), 66$68(2005)$

53. Julien, J.O., Thom, B., Kline, N.E.: Identification of barriers to sexual health assessment in nursing oncology practice. Oncol. Nurs. Forum 37(3), 186-190 (2010) 
54. Bauer, M.W.: Classical content analysis: a review. In: Bauer, M.W., Gaskell, G. (eds.) Qualitative researching with text, image and sound, pp. 51-131. Sage, London (2000)

55. Butler, C., Higgins, S.: Disability. In: das Nair, R., Butler, C. (eds.) Intersectionality, sexuality and psychological therapies exploring lesbian, gay, and bisexual diversity, pp. 39-213. Wiley-BPS Blackwell, London (2012)

56. Dolinska-Zygmunt, G., Nomejko, A.: Sexual satisfaction's contribution to a sense of quality of life in early adulthood. Pol. J. App. Psychol. 9(1), 65-73 (2011)

57. Marwick, C.: Survey says patients expect little physician help on sex. JAMA 281(23), 2132-2174 (1999)

58. Laumann, E.O., Paik, A., Rosen, R.C.: Sexual dysfunction in the United States: prevalence and predictors. JAMA 281, 537-544 (1999)

59. Gott, M., Galena, E., Hinchliff, S., Elford, H.: "Opening a can of worms": GP and practice nurse barriers to talking about sexual health in primary care. Fam. Pract. 21(5), 528-536 (2004)

60. Dattilo, J., Brewer, M.K.: Assessing clients' sexual health as a component of holistic nursing practice: senior nursing students share their experiences. J. Holist. Nurs. 23(2), 208-219 (2005)

61. Matocha, L.K., Waterhouse, J.K.: Current nursing practice related to sexuality. Res. Nurs. Health 16, 371-378 (1993)

62. Hough, S.: Sexuality within the head-injury rehabilitation setting: a staff's perspective. Psychol. Rep. 65, 745-746 (1989)

63. Ducharme, S., Gill, K.M.: Sexual values, training and professional roles. J. Head. Trauma. Rehabil. 5(2), 38-45 (1990)

64. Cellek, S., Giraldi, A.: Challenges in sexual medicine. Nat. Rev. Urol. 9(9), 537-542 (2012)

65. Simpson, G.: Addressing the sexual concerns of persons with traumatic brain injury in rehabilitation settings: a framework for action. Brain Impair. 2(2), 97-108 (2001)

66. Ducharme, S.: Providing sexuality services in head injury rehabilitation centers: Issues in staff training. Int. J. Adolesc. Med. Health. 7(2), 179-191 (1994)

67. Bandura, A.: Self-efficacy mechanism in human agency. Am. Psychol. 37, 122-147 (1982)

68. Annon, J.: The PLISSIT model: a proposed conceptual scheme of the behavioural treatment of sexual problems. J. Sex. Educ. Ther. 2, 1-15 (1976)

69. Taylor, B., Davis, S.: The extended PLISSIT model for addressing the sexual wellbeing of individuals with an acquired disability or chronic illness. Sex. Disabil. 25(3), 135-139 (2007)

70. Davis, S., Taylor, B.: From PLISSIT to ExPLISSIT. In: Davis, S. (ed.) Rehabilitation The Use of Theories and Models, pp. 101-130. Edinburgh, Churchill Livingstone (2006)

71. UKCC: Fitness for Practice. UKCC, London (1999)

72. Rembis, M.A.: Beyond the binary: rethinking the social model of disabled sexuality. Sex. Disabil. 28, 51-60 (2009) 